DOI: $10.17957 / \mathrm{IJAB} / 15.1721$

http://www.fspublishers.org

\title{
Chemical Composition of Essential Oil from Dalbergia odorifera Flowers and HPLC Analysis of Tectorigenin in Its Leaves and Branches
}

\author{
Ziling Mao ${ }^{1 \dagger}$, Yuyang Wang ${ }^{1 \dagger}$, Teng Cai ${ }^{1}$, Jiaxi $\mathrm{Li}^{1}$, Hamza Shahid ${ }^{1}$, Huayi Huang ${ }^{2}$, Minyu Lu ${ }^{1}$, Jun Wang ${ }^{1}$, Dan \\ Wang $^{3 *}$ and Tijiang Shan ${ }^{{ }^{*}}$ \\ ${ }^{1}$ Guangdong Province Key Laboratory of Microbial Signals and Disease Control, College of Forestry and Landscape \\ Architecture, South China Agricultural University, Guangzhou 510642, China \\ ${ }^{2}$ Guangdong Provincial Key Laboratory of Silviculture, Protection and Utilization, Guangdong Academy of Forestry, \\ Guangzhou 510520, China \\ ${ }^{3}$ Shandong Institute of Pomology, Tai'an, Shandong 271000, China \\ *For correspondence: geum307@126.com; tjshanscau@163.com \\ † Contributed equally to this work and are co-first authors \\ Received 02 September 2020; Accepted 22 December 2020; Published 25 January 2021
}

\begin{abstract}
Dalbergia odorifera T. Chen, as an important traditional Chinese medicinal plant, has been used in China over a long history. The chemical composition of volatile oil extracted from the D. odorifera flowers is described for the first time here. The volatile oil was extracted by hydro-distillation, and GC-MS was used for the chemical composition analysis. Tectorigenin, an isoflavonoid, was also isolated from the flowers. The structure of tectorigenin was established based on ${ }^{1} \mathrm{H}$ and ${ }^{13} \mathrm{C}$ NMR and HR-ESI-MS spectrometry. The main components of the volatile oil from the flowers were 4-hydroxy-4-methyl-2-pentanone (28.35\%), phenethyl alcohol (12.17\%), cis-5-ethenyltetrahydro- $\alpha, \alpha-5$-trimethyl-2-furanmethanol $(8.71 \%)$, toluene (7.64\%), $p$ xylene $(5.93 \%)$, benzyl alcohol $(5.72 \%)$ and ethylbenzene $(5.35 \%)$. The tectorigenin contents in the xylem, phloem and leaves were determined by high-performance liquid chromatography (HPLC) as $75.44 \mu \mathrm{g} / \mathrm{g}, 104.26 \mu \mathrm{g} / \mathrm{g}$ and $393.11 \mu \mathrm{g} / \mathrm{g}$, respectively, on a dry weight basis and $49.32 \mu \mathrm{g} / \mathrm{g}, 51.98 \mu \mathrm{g} / \mathrm{g}$ and $74.45 \mu \mathrm{g} / \mathrm{g}$, respectively, on a fresh weight basis. The study provides an important theoretical basis for the further development and application of the D. odorifera flowers and tectorigenin. (C) 2021 Friends Science Publishers
\end{abstract}

Keywords: Dalbergia odorifera; Essential oils; GC-MS; Tectorigenin; HPLC analysis

\section{Introduction}

Dalbergia odorifera T. Chen (Family: Fabaceae) is a valuable tree indigenous to Hainan Province and has been gradually cultivated in South China (Sun et al. 2015; Zhao et al. 2020a). In view of its distinctive color, aromatic trunk, and high density, this valuable rosewood tree is particularly popular for manufacturing luxurious furniture, artifacts, and musical instruments (Tao and Wang 2010; Wariss et al. 2018). The heartwood of D. odorifera as an important traditional Chinese medicine in China has been used to treat cardio- and cerebrovascular diseases for a long time ( $\mathrm{Li}$ et al. 2019; Zhao et al. 2020b). Due to its precious heartwood and medicinal and economic value, $D$. odorifera has been listed on the IUCN red list since 1998 because of the longterm overexploitation (Wariss et al. 2018; Liu et al. 2019).

As an increasingly popular traditional Chinese medicine, D. odorifera species have attracted much attention from phytochemists. Substantial research has been conducted on this species in recent years, and those studies mainly concerned with its chemical constituents and pharmacological activities of the heartwood (The SN 2017). Some previous studies have focused on the biological activities of the heartwood, such as its antimicrobial (Zhao et al. 2011; Wang et al. 2014), anti-inflammatory (Lee et al. 2014; Choi et al. 2017; Kim et al. 2018), antioxidant (Ma et al. 2013; Sun et al. 2015), anti-platelet aggregation (Tao and Wang 2010), angiogenic (Fan et al. 2017), antitumor (Park et al. 2016; Bastola et al. 2017; Meng et al. 2019) and vasodilatory (Sugiyama et al. 2002; Yang et al. 2013) effects. To date, 175 chemical constituents have been isolated from D. odorifera (Meng et al. 2019; Lu et al. 2019). Among them, flavonoids and volatile oils are the major secondary metabolites of $D$. odorifera (Zhao et al. 2000). Most studies on the chemical composition of this species have analyzed the heartwood and leaves and reported the isolation of flavonoids, neoflavonoids, isoflavonoids and other flavonoid derivatives (Barnes 2004; Coon et al. 2007). However, no reports on the secondary metabolites from the flowers have been published.

To cite this paper: Mao Z, Y Wang, T Cai, J Li, H Shahid, H Huang, M Lu, J Wang, D Wang, T Shan (2021). Chemical composition of essential oil from Dalbergia odorifera flowers and HPLC analysis of tectorigenin in its leaves and branches. Intl J Agric Biol 25:723-729 
In this study, we extracted the essential oils of $D$. odorifera flowers, and analyzed using GC-MS. Furthermore, tectorigenin, the main constituent, was isolated first time from the flowers of $D$. odorifera in this study. The antioxidant activities of the crude extracts as well as tectorigenin were also determined. As reported in previous studies, tectorigenin was also isolated from the heartwood and leaves, and the differences in the tectorigenin content among different organs were determined by using HPLC.

\section{Materials and Methods}

\section{General experimental procedures}

NMR spectra were recorded on a Bruker Avance-600 NMR spectrometer (Bruker, USA). HR-ESI-MS was carried out on Bruker maXis with an ESI interface and a Q-TOF mass spectrometer (Bruker, USA). The tectorigenin content was analyzed on a Prominence LC-16 HPLC system (Shimadzu, Japan). HPLC analysis of tectorigenin was performed at $40^{\circ} \mathrm{C}$ using a reversed-phase $\mathrm{C}_{18}$ column (Phenomenex, USA). Acetonitrile and water $(30: 70, \mathrm{v} / \mathrm{v})$ with $0.01 \%$ TFA were used as the mobile phase and pumped at a flow rate of $1.0 \mathrm{~mL} / \mathrm{min}$ for isocratic elution, with UV detection at 265 $\mathrm{nm}$. Water was purified by an ultrapure water machine (Exceed-Cb-10, Aike, China). Acetonitrile was of HPLC grade.

\section{Plant material and determination of the water content}

Leaves, fresh flowers and current-growth branches of $D$. odorifera were manually collected in the campus of South China Agricultural University (SCAU) from 16-year-old artificially cultivated D. odorifera in May 2018, in Guangzhou, China. The taxonomical identification of the plant materials was performed by Dr. Mingxuan Zheng of College of Forestry and Landscape Architecture (SCAU, Guangzhou, China), where the voucher specimen (SCAULPMH-180518) of the plant was deposited.

The collected plant materials were first cleaned, and the dirt was removed. Then, the xylem and phloem of the current-growth branches were separated. The leaves, xylem and phloem were cut into small pieces and dried in an oven at $50^{\circ} \mathrm{C}$. This process was repeated three times for each sample. The material was weighed before (wet weight) and after (dry weight) drying in the oven for several hours. The materials were dried until a constant weight was reached. The water content was calculated as:

$$
\left[\left(\text { Mass }_{\text {wet weight }}-\text { Mass }_{\text {dry weight }}\right) / \text { Mass }_{\text {wet weight }}\right] \times 100 \%
$$

\section{Preparation, GC and GC-MS analysis of the flower essential oil}

The volatile oil was extracted from the flowers $(0.52 \mathrm{~kg})$ of $D$. odorifera by hydro-distillation as our previous reported
(Feng et al. 2017). GC and GC-MS were carried out by the same column and analysis conditions. The oven temperature was programmed as our previous reported (Feng et al. 2017).

\section{Extraction of secondary metabolites from the flowers}

Three different methods were used to extract secondary metabolites from the $D$. odorifera flowers. Fresh flowers from $D$. odorifera were extracted three times with ethyl acetate $(\mathrm{EtOAc})$ at room temperature. The EtOAc extracts were dried under vacuum to obtain the crude extracts (sample 1). After extraction of the essential oils, the residue and water were separated by decreasing the temperature to room temperature. The flower residue was also extracted three times with EtOAc at room temperature. The EtOAc extracts were dried under vacuum to obtain sample 2. The water was first concentrated under vacuum and then extracted three times with EtOAc, and the EtOAc extracts were dried under vacuum to obtain sample 3.

\section{Antioxidant activity analysis}

Samples 1-3 were further evaluated the antioxidant activities. The radical-scavenging activity was determined with a spectrophotometric microplate method based on the reduction of a methanolic solution of DPPH according to our previous report (Shan et al. 2020).

\section{Extraction and fractionation of tectorigenin}

Sample 3 was a yellow solid and mainly contained one compound as identified on the basis of the HPLC analysis. Therefore, sample 3 was purified by recrystallization and repeated until the compound was purified. Finally, the recrystallized compound was chromatographed on a Sephadex LH-20 column with $\mathrm{MeOH}-\mathrm{CHCl}_{3}(1: 1, \mathrm{~V} / \mathrm{V})$ to afford tectorigenin (14 mg).

\section{Preparation of tectorigenin standard solutions}

Tectorigenin (1 mg) was accurately weighed and placed in a $2 \mathrm{~mL}$ centrifuge tube, where it was dissolved in $1 \mathrm{~mL}$ of methanol and the mother solution was $1000 \mu \mathrm{g} / \mathrm{mL}$. The mother solution was then diluted to $250 \mu \mathrm{g} / \mathrm{mL} \sim 0.9765625$ $\mu \mathrm{g} / \mathrm{mL}$ with methanol using double and half dilution method, and stored at $4^{\circ} \mathrm{C}$ before use.

\section{Preparation of sample solutions}

D. odorifera xylem, phloem and leaves were extracted three times with EtOAc at room temperature to obtain crude extracts. Each sample solution was filtered (pore size, 0.22 $\mu \mathrm{m})$ and then dissolved in methanol to attain a concentration of $25 \mathrm{mg} / \mathrm{mL}$. 


\section{Method validation}

The HPLC-UV method was validated according to the procedures described in ICH guidelines Q2 (R1) (ICH Harmonised Tripartite Guideline 2005) and our previous report (Shan et al. 2012) to validate the analytical methods.

\section{Quantitative determination of tectorigenin in leaves and branches}

The contents of tectorigenin in the samples, xylem, phloem and leaves of $D$. odorifera were determined by HPLC-UV. The crude extracts for the HPLC analysis were prepared as described above. The obtained peak area of tectorigenin was substituted into the regression equation to obtain the concentration and the RSD was calculated.

\section{Statistical analysis}

All experiments were carried out in triplicate and the data obtained were compared among treatments using one-way analysis of variance (ANOVA SAS 9.4, SAS Institute, Cary, NC). Tukey's Honest Significant Differences (HSD) tests were conducted after each ANOVA for multiple comparisons. The significance level was determined at $p$ $=0.05$ for all tests.

\section{Results}

\section{Essential oil analysis}

Fig. 1 shows the total ion chromatogram of the essential oil from the flowers of $D$. odorifera. The yield of volatile oil from the hydro-distillation of $D$. odorifera flowers was $0.082 \%$ (w/w, fresh weight). The GC-MS results are presented in Table 1. Sixteen components were identified in the essential oil from $D$. odorifera flowers and made up $96.00 \%$ of the volatile oil. Of them, the main components were 4-hydroxy-4-methyl-2-pentanone (28.35\%), phenethyl alcohol (12.17\%), cis-5-ethenyltetrahydro- $\alpha, \alpha$-5-trimethyl2-furanmethanol $(8.71 \%)$, toluene $(7.64 \%), \quad p$-xylene (5.93\%), benzyl alcohol (5.72\%) and ethylbenzene (5.35\%), and the relative contents of these compounds accounted for $73.87 \%$ of the total oil content. The relative percentages of the remaining components were below 5\%. The essential oils from $D$. odorifera flowers were mainly consisted of alcohols, hydrocarbons, ketones and nitrogenous compounds on the basis of these data shown in Table 1.

\section{Antioxidant activity}

Samples 1-3 were submitted a DPPH free radical scavenging assay (Table 2). Sample 3 displayed the highest antioxidant activity with an $\mathrm{IC}_{50}$ of $0.35 \mu \mathrm{g} / \mathrm{mL}$, which is higher than the $\mathrm{IC}_{50}$ of BHT, $7.14 \mu \mathrm{g} / \mathrm{mL}$. Interestingly, both samples 1 and 2 displayed weak antioxidant activity,

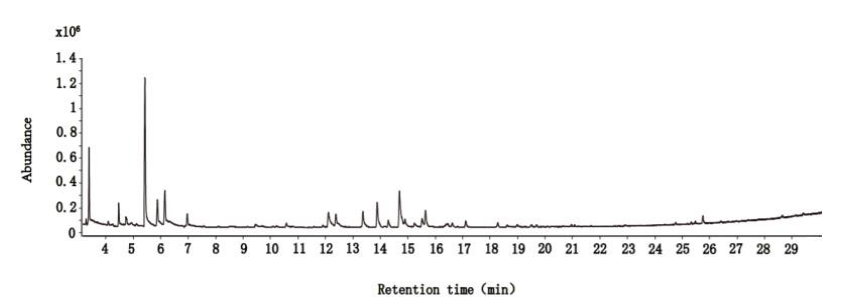

Fig. 1: Total ion chromatogram (TIC) of essential oil from the flowers of D. odorifera

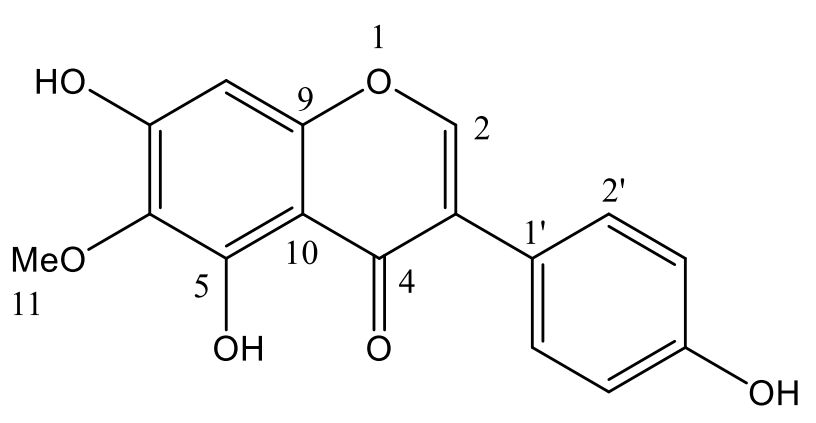

Fig. 2: The chemical structure of tectorigenin

with $\mathrm{IC}_{50}$ values greater than $200 \mu \mathrm{g} / \mathrm{mL}$. Sample 3 was derived from the water remaining after extraction of the essential oil and contained compounds with high antioxidant activity, prompting further study.

\section{Elucidation of the purified tectorigenin}

As described above, sample 3 displayed the highest antioxidant activity and was therefore further purified by recrystallization and a Sephadex LH-20 column. The molecular formula of tectorigenin, $\mathrm{C}_{16} \mathrm{H}_{12} \mathrm{O}_{6}$, was assigned by HR-ESI-MS (Fig. S1): m/z $301.0706[\mathrm{M}+\mathrm{H}]^{+}$(calcd. 301.0707) and $\mathrm{m} / \mathrm{z} 323.0526[\mathrm{M}+\mathrm{Na}]^{+}$(calcd. 323.0526). After comparing the obtained ${ }^{1} \mathrm{H}$ and ${ }^{13} \mathrm{C}$ NMR (shown in Table 3) and HR-ESI-MS data with those reported in the literature (Lee et al. 2004), this compound was identified as tectorigenin, and its structure is shown in Fig. 2. Tectorigenin was obtained as a yellow powder $(\mathrm{MeOH})$. However, tectorigenin did not show antioxidant activity at $200 \mu \mathrm{g} / \mathrm{mL}$ (results not shown).

\section{Identification of tectorigenin by HPLC-UV}

The chromatograms of the tectorigenin standard, the real sample solution and the mixed standard solution are shown in Fig. 3. Tectorigenin could be distinguished based on its retention times. Fig. 3 (A) shows the HPLC-UV profile of the tectorigenin standard. The retention time of tectorigenin was 18.50 min when isocratically eluted with $\mathrm{MeCN}-\mathrm{H}_{2} \mathrm{O}$ (30:70) containing $0.01 \%$ TFA, with detection at $265 \mathrm{~nm}$. Fig. 3 (B)-(D) shows the HPLC-UV profiles of the EtOAc 
Table 1: Chemical composition of the essential oil from the flowers of $D$. odorifera

\begin{tabular}{|c|c|c|c|c|c|}
\hline No. & Retention time & Compound & Molecular formula & Molecular weight & RA $(\%)^{a}$ \\
\hline 1 & 3.389 & Toluene & $\mathrm{C}_{7} \mathrm{H}_{8}$ & 92 & 7.64 \\
\hline 2 & 4.470 & Acetic acid, butyl ester & $\mathrm{C}_{6} \mathrm{H}_{12} \mathrm{O}_{2}$ & 116 & 3.04 \\
\hline 3 & 4.731 & 1-Cyclopropyl-1-methyl-ethylamine & $\mathrm{C}_{6} \mathrm{H}_{13} \mathrm{~N}$ & 99 & 1.58 \\
\hline 4 & 5.426 & 4-Hydroxy-4-methyl-2-pentanone & $\mathrm{C}_{6} \mathrm{H}_{12} \mathrm{O}_{2}$ & 116 & 28.35 \\
\hline 5 & 5.879 & Ethylbenzene & $\mathrm{C}_{8} \mathrm{H}_{10}$ & 106 & 5.35 \\
\hline 6 & 6.148 & $p$-Xylene & $\mathrm{C}_{8} \mathrm{H}_{10}$ & 106 & 5.93 \\
\hline 7 & 6.965 & $o$-Xylene & $\mathrm{C}_{8} \mathrm{H}_{10}$ & 106 & 1.95 \\
\hline 8 & 12.108 & Benzyl alcohol & $\mathrm{C}_{7} \mathrm{H}_{8} \mathrm{O}$ & 108 & 5.72 \\
\hline 9 & 12.380 & Benzeneacetaldehyde & $\mathrm{C}_{8} \mathrm{H}_{8} \mathrm{O}$ & 120 & 4.01 \\
\hline 10 & 13.887 & cis-5-Ethenyltetrahydro- $\alpha, \alpha$-5-trimethyl-2-furanmethanol & $\mathrm{C}_{10} \mathrm{H}_{18} \mathrm{O}_{2}$ & 170 & 8.71 \\
\hline 11 & 14.291 & Linalool & $\mathrm{C}_{10} \mathrm{H}_{18} \mathrm{O}$ & 154 & 1.58 \\
\hline 12 & 14.696 & Phenethyl alcohol & $\mathrm{C}_{8} \mathrm{H}_{10} \mathrm{O}$ & 122 & 12.17 \\
\hline 13 & 14.899 & Isophorone & $\mathrm{C}_{9} \mathrm{H}_{14} \mathrm{O}$ & 138 & 2.31 \\
\hline 14 & 15.520 & Benzyl nitrile & $\mathrm{C}_{8} \mathrm{H}_{7} \mathrm{~N}$ & 117 & 2.19 \\
\hline 15 & 15.645 & 2,6,6-Trimethyl-2-cyclohexene-1,4-dione & $\mathrm{C}_{9} \mathrm{H}_{12} \mathrm{O}_{2}$ & 152 & 4.01 \\
\hline 16 & 25.753 & 2,4-Di-tert-butylphenol & $\mathrm{C}_{14} \mathrm{H}_{22} \mathrm{O}$ & 206 & 1.46 \\
\hline
\end{tabular}

Table 2: Antioxidant activities

\begin{tabular}{lr}
\hline Samples & $\mathrm{IC}_{50}(\mu \mathrm{g} / \mathrm{mL})$ \\
\hline Sample 1 & $246.78 \pm 0.99 \mathrm{~b}$ \\
Sample 2 & $316.98 \pm 2.52 \mathrm{a}$ \\
Sample 3 & $0.35 \pm 0.01 \mathrm{~d}$ \\
BHT & $7.14 \pm 0.08 \mathrm{c}$ \\
\hline Mean + standard deviation. Values with same letter differ non-significantly $(\mathrm{P}>0.05)$
\end{tabular}

Table 3: ${ }^{13} \mathrm{C}-\mathrm{NMR}$ and ${ }^{1} \mathrm{H}-\mathrm{NMR}$ data for tectorigenin (in DMSO- $d_{6}$ )

\begin{tabular}{lcc}
\hline Position & \multicolumn{2}{c}{$1(\delta$ in ppm, $J$ in Hz $)$} \\
\cline { 2 - 3 } & $\delta_{\mathrm{C}}$ & $\delta_{\mathrm{H}}$ \\
\hline 2 & 154.0 & $8.33(1 \mathrm{H}, \mathrm{s})$ \\
3 & 121.8 & - \\
4 & 180.5 & - \\
5 & 152.7 & - \\
$5-\mathrm{OH}$ & - & $13.05(1 \mathrm{H}, \mathrm{s})$ \\
6 & 131.4 & - \\
7 & 153.2 & - \\
$7-\mathrm{OH}$ & - & $9.59(1 \mathrm{H}, \mathrm{s})$ \\
8 & 93.8 & $6.50(1 \mathrm{H}, \mathrm{s})$ \\
9 & 157.5 & - \\
10 & 104.8 & - \\
$1^{\prime}$ & 59.9 & $3.75(3 \mathrm{H}, \mathrm{s})$ \\
$1^{\prime}$ & 121.2 & - \\
$2^{\prime}, 6^{\prime}$ & 130.1 & $7.37(2 \mathrm{H}, \mathrm{d}, J=8.5 \mathrm{~Hz})$ \\
$3^{\prime}, 5^{\prime}$ & 115.0 & $6.82(2 \mathrm{H}, \mathrm{d}, J=8.5 \mathrm{~Hz})$ \\
$4^{\prime}$ & 157.4 & - \\
\hline
\end{tabular}

extracts of the xylem, phloem and leaves, respectively. The tectorigenin peak eluted at $18.50 \mathrm{~min}$ for all three samples. A tectorigenin standard was added to crude extracts and analyzed to confirm the peak at 18.50 min. Fig. 3 (E)-(G) shows the HPLC profiles of the crude xylem, phloem and leaf extracts containing the tectorigenin standard. The peak at $18.50 \mathrm{~min}$ in Fig. $3(\mathrm{E})-(\mathrm{G})$ was significantly higher than that in Fig. 3 (B)-(D). Therefore, the peak at $18.50 \mathrm{~min}$ in Fig. 3 (B)-(D) corresponded to tectorigenin.

\section{Calibration curves}

Based on the above results, tectorigenin was further selected for quantitative analysis by HPLC-UV. The linear equation was $Y=3398998.33 X-2834.37(R=0.9994)$, where $X$ represent the quantity $(\mu \mathrm{g})$ of the sample injected for one time, $Y$ represent the peak area, and $R$ is the correlation coefficient. The $R$ value showed a good linearity over a range of $0.009765625 \sim 2.5 \mu \mathrm{g}$ of injected sample.

\section{Precision}

The mean RSDs in the tectorigenin content for intra- and interday detection at three different levels (Table 4) were less than $1.09 \%$ and $1.43 \%$, respectively. Because these values are below $2.0 \%$, the method has good reproducibility.

\section{Accuracy}

The accuracy was calculated as the means of a standard addition experiment and the result was shown in Table 5. The mean recovery $(n=9)$ of tectorigenin in xylem, phloem and leaves were $95.99 \%, 96.87 \%$ and $100.50 \%$, respectively, and the mean RSDs were $0.79 \%, 0.72 \%$ and $0.80 \%$, respectively. These satisfactory recoveries and low RSDs confirmed the suitability of this method for the analysis of tectorigenin.

\section{LOD and LOQ}

Under the validated HPLC conditions, the LOD and LOQ were determined at an S/N values of approximately 3 and 10 , respectively, from injections of 0.9342 and $1.3023 \mathrm{ng}$, respectively.

\section{Quantitative determination of tectorigenin in leaves and branches}

The water contents are shown in Table 6. The water content in leaves was the highest, followed by that in phloem and then that in xylem, with values of $81.05,49.52$ and $34.63 \%$, respectively. The content of tectorigenin was calculated in leaves and branches on the basis of the water content, as 
Analysis of Essential Oil and Tectorigenin in Dalbergia odorifera / Intl J Agric Biol, Vol 25, No 3, 2021

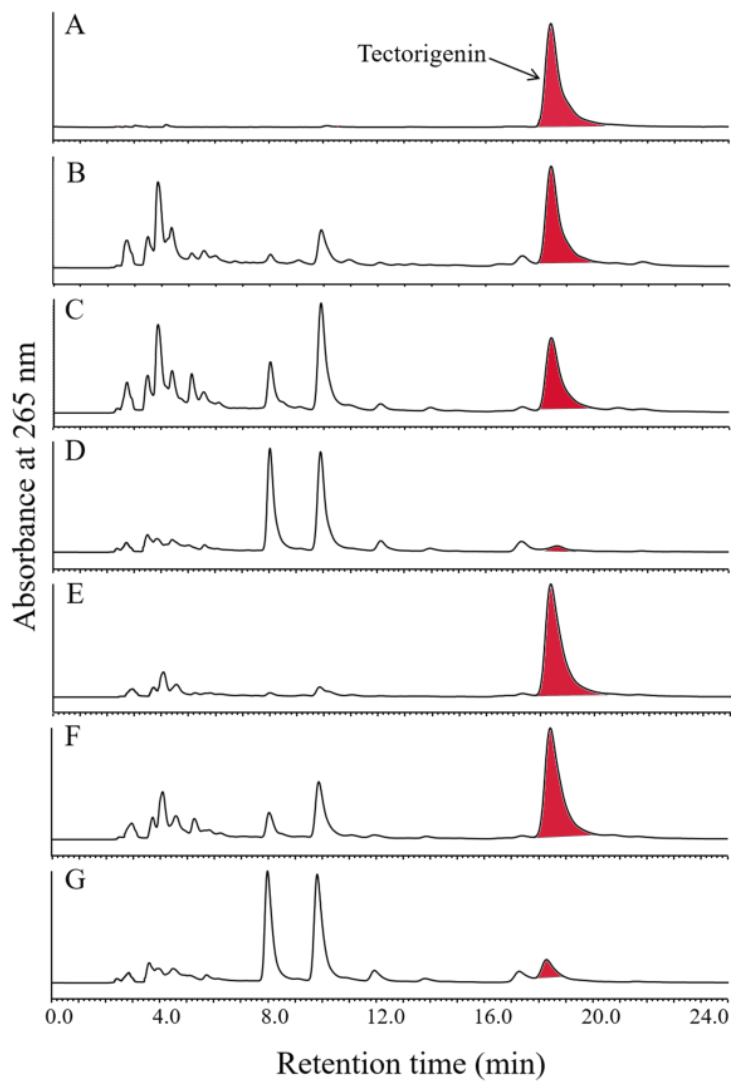

Fig. 3: HPLC-UV analysis of tectorigenin in xylem, phloem and leaves of $D$. odorifera

(A) HPLC profile of the tectorigenin standard; (B)-(D) HPLC profiles of the crude xylem, phloem and leaf extracts, respectively (E)-(G) HPLC profiles of the crude xylem, phloem and leaf extracts containing the tectorigenin standard, respectively

shown in Table 7. The content of tectorigenin in the xylem, phloem and leaves was $75.44,104.26$ and $393.11 \mu \mathrm{g} / \mathrm{g}$, respectively, on a dry weight basis and $49.32,51.98$ and $74.45 \mu \mathrm{g} / \mathrm{g}$, respectively, on a fresh weight basis.

\section{Discussion}

Volatile oil is an important component of $D$. odorifera. To the best of our knowledge, the heartwoods are a valuable source of essential oils that can be used as a precious perfume fixative. In previous studies, the volatile oils obtained from $D$. odorifera leaves, heartwood and seeds were analyzed and reported. 2-methoxy-4-vinylphenol and $n$-hexadecanoic acid with the relative percentages 21.73 and $13.97 \%$, respectively, were the major compounds in volatile oil from leaves (Bi et al. 2004). Liu (2009) reported the major components of the volatile oil obtained from heartwood via steam distillation were nerolidol and caryophyllene oxide, and the relative percentages were 57.36 and $22.22 \%$, respectively. Guo et al. (2011) analyzed the chemical composition of the seeds essential oil and the main components were $p, p, p$-triphenyl phosphine imide and bis(1-methylethyl) peroxide with the relative
Table 4: Precision and RSDs of the determination of tectorigenin by HPLC

\begin{tabular}{ccccc}
\hline Compound & \multicolumn{2}{c}{ Intraday $(\mathrm{n}=5)$} & \multicolumn{2}{c}{ Interday $(\mathrm{n}=9)$} \\
\cline { 2 - 5 } & $\begin{array}{c}\text { Concentration } \\
(\mu \mathrm{g} / \mathrm{mL})\end{array}$ & $\begin{array}{c}\text { RSD } \\
(\%)\end{array}$ & $\begin{array}{c}\text { Concentration } \\
(\mu \mathrm{g} / \mathrm{mL})\end{array}$ & $\begin{array}{c}\text { RSD } \\
(\%)\end{array}$ \\
\hline Tectorigenin & 3.91 & 1.09 & 3.91 & 1.17 \\
& 31.25 & 0.50 & 31.25 & 1.43 \\
& 250.00 & 0.38 & 250.00 & 1.12 \\
\hline
\end{tabular}

Table 5: Recoveries and RSDs of tectorigenin in leaves and branches

\begin{tabular}{lccc}
\hline Sample & Added concentration $(\mu \mathrm{g} / \mathrm{mL})$ & Recovery $(\%)$ & RSD $(\%)$ \\
\hline Xylem & $0.5 \mathrm{X}$ & 95.21 & 0.44 \\
& $1.0 \mathrm{X}$ & 98.42 & 1.45 \\
\multirow{4}{*}{ Phloem } & $2.0 \mathrm{X}$ & 94.33 & 0.49 \\
& $0.5 \mathrm{X}$ & 97.41 & 1.02 \\
& $1.0 \mathrm{X}$ & 96.38 & 0.70 \\
\multirow{3}{*}{ Leaf } & $2.0 \mathrm{X}$ & 96.83 & 0.45 \\
& $0.5 \mathrm{X}$ & 101.10 & 1.09 \\
& $1.0 \mathrm{X}$ & 100.34 & 0.81 \\
& $2.0 \mathrm{X}$ & 100.05 & 0.49 \\
\hline
\end{tabular}

Table 6: Water content of xylem, phloem and leaves

\begin{tabular}{lc}
\hline Samples & Water content $(\%)$ \\
\hline Xylem & $34.63 \pm 0.55 \mathrm{c}$ \\
Phloem & $49.52 \pm 3.02 \mathrm{~b}$ \\
Leaf & $81.05 \pm 0.78 \mathrm{a}$ \\
\hline Mean \pm standard deviation. Values with same letter differ non-significantly $(\mathrm{P}>0.05)$
\end{tabular}

Table 7: Contents and RSDs of tectorigenin in leaves and branches

\begin{tabular}{lrcc}
\hline Samples & Average $(\mu \mathrm{g} / \mathrm{g}$ dry weight $)$ & Average $(\mu \mathrm{g} / \mathrm{g}$ fresh weight $)$ & $\mathrm{RSD}(\%)$ \\
\hline Xylem & $75.44 \pm 0.63 \mathrm{c}$ & $49.32 \pm 0.41 \mathrm{c}$ & 0.83 \\
Phloem & $104.26 \pm 1.38 \mathrm{~b}$ & $51.98 \pm 0.69 \mathrm{~b}$ & 1.32 \\
Leaf & $393.11 \pm 2.57 \mathrm{a}$ & $74.45 \pm 0.49 \mathrm{a}$ & 0.65 \\
\hline \multicolumn{4}{l}{ Mean \pm standard deviation. Values with same letter differ non-significantly $(\mathrm{P}>0.05)$}
\end{tabular}

percentages 35.3 and $16.4 \%$, respectively. As can be seen from the report above, the major constituents in $D$. odorifera leaves differ from those in the heartwood and seed oil. However, the chemical composition of volatile oil from $D$. odorifera flowers has not been reported. In this study, the volatile oil of $D$. odorifera flowers, extracted by steam distillation and analyzed by GC-MS, revealed the following main components: 4-hydroxy-4-methyl-2-pentanone, phenethyl alcohol, cis-5-ethenyltetrahydro- $\alpha, \alpha-5$-trimethyl2-furanmethanol, toluene, $p$-xylene, benzyl alcohol and ethylbenzene. The present analysis also showed that the types and relative contents of the volatile oil components varied greatly in different parts of plant tissues. In addition, the chemical composition also varies according to the extraction method.

Flavonoids are considered the important active principle components in many herbs because of the extensive pharmacological activities (Zhao et al. 2020a). As previously reported, flavonoids are the main secondary metabolites and about 99 flavonoids have been identified from $D$. odorifera (Zhao et al. 2020b). In previous reports, pharmacological studies revealed flavonoids to be antioxidant components 
and parts of flavonoids displayed stronger antioxidant activity than those of BHT (Wang et al. 2000; Hou et al. 2011). In this study, the extract of $D$. odorifera flowers was found to contain tectorigenin, an isoflavone that did not show any antioxidant activity in the DPPH assay. At present, no reports have described the antioxidant activity of tectorigenin. The above results from other studies are consistent with our results in this study. Sample 3 from the flowers of $D$. odorifera in this study displayed significant in vitro antioxidant activity, but the active components remain unknown. Therefore, the active antioxidant constituents of $D$. odorifera flowers should be elucidated in the future.

This investigation has shed light on utilization of the flowers from $D$. odorifera, a Chinese medicinal plant of greater economic and ecological importance, for the study of essential oils and secondary metabolites. This study is the first of its kind in this plant species which involves the use of flowers for biochemical analysis, unlike previous studies which were primarily focused on heartwood. The evidence also suggests that tectorigenin as the major plant metabolite in flower tissues which needs further functional studies and can prove to be very useful.

\section{Conclusion}

The is the first study to clarify chemical composition of volatile oil from flowers of $D$. odorifera and to identify tectorigenin as the key constituent in the flowers secondary metabolites. The main components of the volatile oil from D. odorifera flowers were 4-hydroxy-4-methyl-2pentanone, phenethyl alcohol, cis-5-ethenyltetrahydro- $\alpha, \alpha$ 5-trimethyl-2-furanmethanol, toluene, $p$-xylene, benzyl alcohol and ethylbenzene. The distribution of tectorigenin in branches of $D$. odorifera was also analyzed. The tectorigenin contents in the xylem, phloem and leaves were determined by HPLC to be $75.44 \mu \mathrm{g} / \mathrm{g}, 104.26 \mu \mathrm{g} / \mathrm{g}$ and $393.11 \mu \mathrm{g} / \mathrm{g}$, respectively, on a dry weight basis and 49.32 $\mu \mathrm{g} / \mathrm{g}, 51.98 \mu \mathrm{g} / \mathrm{g}$ and $74.45 \mu \mathrm{g} / \mathrm{g}$, respectively, on a fresh weight basis. This information will pave the way for further functional analysis, experimentation, development and application of $D$. odorifera flowers with keen focus on tectorigenin as an important antioxidant agent.

\section{Acknowledgements}

We thank Hao Zhai and Fan Zhang for the suggestions that greatly improved the manuscript. This research was cofinanced by the Forestry Science and Technology Innovation Project of Guangdong Province (2020KJCX004) and the Province Natural Science Foundation of Guangdong (2019A1515011554).

\section{Author Contributions}

ZM, YW and TS performed the research and recorded the spectra. ML, TC, JL, HH, TS and DW prepared the flower essential oils and performed the GC-MS analysis. $\mathrm{ZM}, \mathrm{YW}$ and TS isolated and structurally characterized tectorigenin. HS and JW performed the antioxidant assay. TS, TC, JL and HS performed the HPLC analysis of tectorigenin. TS, YW and CT contributed to the data collection process. TS and DW contributed by preparing figures. TS, DW and ZM designed the research. TS, YW, DW and ZM completed the draft of the manuscript. All the authors contributed to the writing, editing and revising of the manuscript.

\section{References}

Barnes S (2004). Soy isoflavones-phytoestrogens and what else? J Nutr 134:1225-1228

Bastola T, RB An, YC Kim, J Kim, J Seo (2017). Cearoin induces autophagy, ERK activation and apoptosis via ROS generation in $\mathrm{SH}$ SY5Y neuroblastoma cells. Molecules 22; Article 242

Bi HP, XP Song, CR Han, X Xu, H Zhong (2004). Studies on the chemical constituents of the essential oil from the leaves of Dalbergia odorifera T. Chen. J Chin Med Mater 27:733-734

Choi HS, JA Park, JS Hwang, SA Ham, T Yoo, WJ Lee, KS Peak, HC Shin, CH Lee, HG Seo (2017). A Dalbergia odorifera extract improves the survival of endotoxemia model mice by inhibiting HMGB1 release. BMC Complem Altern Med 17; Article 212

Coon JT, MH Pittler, E Ernst (2007). Trifolium pratense isoflavones in the treatment of menopausal hot flushes: A systematic review and metaanalysis. Phytomedicine 14:153-159

Fan ZM, DY Wang, JM Yang, ZX Lin, AL Yang, H Fan, M Cao, SY Yuan, ZJ Liu, X Zhou, YH Wang (2017). Dalbergia odorifera, extract promotes angiogenesis through upregulation of VEGFRs and PI3K/MAPK signaling pathways. $J$ Ethnopharmacol 204:132-141

Feng H, Y Zhu, W Wang, Y Liu, J He, J Wang, T Shan (2017). Chemical composition and antibacterial activity of the volatile oils from Melaleuca bracteata. Plant Prot 43:189-192

Guo X, LH Zheng, M Chai, PJ Zhu, ZM Chen (2011). Study on chemistry composition of essential oil from the seeds of Dalbergia Odorifera T. Chen extracted by two methods. Sci Technol Food Ind 32:95-98

Hou JP, H Wu, CT Ho, XC Weng (2011). Antioxidant activity of polyphenolic compounds from Dalbergia odorifera T. Chen. Pak J Nutr 10:694-701

ICH Harmonised Tripartite Guideline. Validation of Analytical Procedures (2005). Text and Methodology Q2 (R1). In Proceedings of the International Conference on Harmonization, London, UK

Kim DC, DS Lee, W Ko, KW Kim, HJ Kim, CS Yoon, H Oh, YC Kim (2018). Heme oxygenase-1-inducing activity of 4methoxydalbergione and 4'-hydroxy-4-methoxydalbergione from Dalbergia odorifera and their anti-inflammatory and cytoprotective effects in murine hippocampal and BV2 microglial cell line and primary rat microglial cells. Neurotox Res 33:337-352

Lee DS, KS Kim, W Ko, B Li, S Keo, GS Jeong, H Oh, YC Kim (2014). The neoflavonoid latifolin isolated from $\mathrm{MeOH}$ extract of Dalbergia odorifera attenuates inflammatory responses by inhibiting NF- $\kappa \mathrm{B}$ activation via Nrf2-mediated heme oxygenase-1 expression. Phytother Res 28:1216-1223

Lee S, SC Lee, J Ryu, D Son, KS Kim, BK Kim (2004). Decursin from the rhizome of Belamcanda chinensis. Nat Prod Sci 10:89-91

Li F, JL Duan, MN Zhao, SJ Huang, F Mu, J Su, KD Liu, Y Pan, XM Lu, J Li, PF Wei, MM Xi, A.D Wen (2019). A network pharmacology approach to reveal the protective mechanism of Salvia miltiorrhizaDalbergia odorifera coupled-herbs on coronary heart disease. Sci Rep 9; Article 19343

Liu FM, Z Hong, DP Xu, HY Jia, NN Zhang, XJ Liu, ZJ Yang, MZ Lu (2019). Genetic diversity of the endangered Dalbergia odorifera revealed by SSR markers. Forests 10; Article 225 
Liu HL (2009). Analysis of the volatile oil from Dalbergiae odoriferae by GC-MS. Chin Tradit Pat Med 31:915-917

$\mathrm{Lu} \mathrm{L}, \mathrm{W} \mathrm{Li}, \mathrm{H}$ Xie (2019). Non-flavonoid constituents from the leaves of Dalbergia odorifera. J Trop Subtrop Bot 27:213-218

Ma FY, CB Gu, CY Li, M Luo, W Wang, YG Zu, J Li, YJ Fu (2013). Microwave-assisted aqueous two-phase extraction of isoflavonoids from Dalbergia odorifera T. Chen leaves. Sep Purif Technol 115:136-144

Meng H, DL Chen, Y Yang, YY Liu, JH Wei (2019). Sesquiterpenoids with cytotoxicity from heartwood of Dalbergia odorifera. J Asian Nat Prod Res 21:954-960

Park KR, HM Yun, TH Quang, H Oh, QS Auh, EC Kim (2016). 4 Methoxydalbergione suppresses growth and induces apoptosis in human osteosarcoma cells in vitro and in vivo xenograft model through down-regulation of the JAK2/STAT3 pathway. Oncotarget 7:6960-6971

Shan TJ, WB Sun, H Liu, S Gao, SQ Lu, M Wang, ZY Chen, S Wang, LG Zhou (2012). Determination and analysis of ustiloxins A and B by LC-ESI-MS and HPLC in false smut balls of rice. Intl $J \mathrm{Mol} \mathrm{Sci}$ 13:11275-11287

Shan TJ, YY Wang, S Wang, YY Xie, ZH Cui, CY Wu, J Sun, J Wang, ZL Mao (2020). A new $p$-terphenyl derivative from the insect-derived fungus Aspergillus candidus Bdf-2 and the synergistic effects of terphenyllin. Peer J 8; Article e8221

Sugiyama A, BM Zhu, A Takahara, Y Satoh, K Hashimoto (2002). Cardiac effects of Salvia miltiorrhiza/Dalbergia odorifera mixture, an intravenously applicable Chinese medicine widely used for patients with ischemic heart disease in China. Circ J 66:182-184

Sun AH, JS Hwang, ES Kang, T Yoo, HH Lim, WJ Lee, KS Paek, HG Seo (2015). Ethanol extract of Dalbergia odorifera protects skin keratinocytes against ultraviolet B-induced photoaging by suppressing production of reactive oxygen species. Biosci Biotechnol Biochem 79:760-766
Tao Y, Y Wang (2010). Bioactive sesquiterpenes isolated from the essential oil of Dalbergia odorifera T. Chen. Fitoterapia 81:393-396

The SN (2017). A review on the medicinal plant Dalbergia odorifera species: Phytochemistry and biological activity. Evid-Based Compl Alt 2017; Article 7142370

Wang H, WH Dong, WJ Zuo, ZK Guo, LL Chen, HM Zhong, HF Dai (2014). Three new phenolic compounds from Dalbergia odorifera. $J$ Asian Nat Prod Res 16:1109-1118

Wang W, XC Weng, DL Cheng (2000). Antioxidant activities of natural phenolic components from Dalbergia odorifera T. Chen. Food Chem 71:45-49

Wariss HM, TS Yi, H Wang, R Zhang (2018). Characterization of the complete chloroplast genome of Dalbergia odorifera (Leguminosae), a rare and critically endangered legume endemic to China. Conserv Genet Resour 10:527-530

Yang ZH, C Mei, XH He, XB Sun (2013) Advance in studies on chemical constitutions, pharmacological mechanism and pharmacokinetic profile of Dalbergia odorifera Lignum. China J Chin Mater Med 38:1679-1683

Zhao Q, JX Guo, YY Zhang (2000). Chemical and pharmacological research progress of Chinese drug "JiangXiang" (lignum Dalbergiae odorifera). J Chin Pharm Sci 9:1-5

Zhao XB, WL Mei, MF Gong, WJ Zuo, HJ Bai, HF Dai (2011). Antibacterial activity of the flavonoids from Dalbergia odorifera on Ralstonia solanacearum. Molecules 16: 9775-9782

Zhao XS, SH Zhang, D Liu; MH Yang, JH Wei (2020a). Analysis of flavonoids in Dalbergia odorifera by ultra-performance liquid chromatography with tandem mass spectrometry. Molecules 25; Article 389

Zhao XS, CH Wang, H Meng, ZX Yu, MH Yang, JH Wei (2020b). Dalbergia odorifera: A review of its traditional uses, phytochemistry, pharmacology and quality control. $J$ Ethnopharmacol 248; Article 112328 